\title{
Evolutionary Game of Social Network for Emergency Mobilization (SNEM) of Magnitude Emergencies: Evidence from China
}

\author{
Rui Nan (D), Jingjie Wang ${ }^{(D)}$, and Wenjun Zhu \\ School of Law and Humanities, China University of Mining and Technology, Beijing 100083, China \\ Correspondence should be addressed to Rui Nan; nr19841018@163.com
}

Received 10 June 2021; Revised 9 October 2021; Accepted 5 January 2022; Published 29 January 2022

Academic Editor: Fei Xiong

Copyright ( 92022 Rui Nan et al. This is an open access article distributed under the Creative Commons Attribution License, which permits unrestricted use, distribution, and reproduction in any medium, provided the original work is properly cited.

\begin{abstract}
As a common social network, the SNEM plays an important role in emergency management. Magnitude emergencies are characterized by high complexity and uncertainty, and it is impossible to rely on the government for emergency management alone. We should absorb multiple subjects to build the SNEM and carry out extensive emergency mobilization in the whole society. The SNEM can integrate resources, gather consensus, promote participation, and reduce risks. The analysis of the types, generation mechanism, subject behavior, and strategy selection of the SNEM aid in adopting appropriate mobilization strategy based on magnitude emergencies, achieving the adaptation of the SNEM and emergency scenarios. By constructing the evolutionary game model of the SNEM for magnitude emergencies, taking China as an empirical sample, this paper explores the behavior evolution law and stable strategy of the government, social organizations, and the public. The results showed that the symbiotic SNEM with a positive response of social organizations and the public under the path of high-intensity mobilization by the government is the best strategy combination, and it is conducive to maximizing the emergency joint force.
\end{abstract}

\section{Introduction}

The social network is a collection of multiple points (social actors) and connections between points (relationships between actors). They coordinate resources, transmit information, provide services, and solve problems through conscious coordination and cooperation $[1,2]$. The SNEM is also a type of social network formed by internal and intersubjects of emergency mobilization through the information exchange and mutual assistance of resources in the context of emergency mobilization for magnitude emergencies. The SNEM plays a pivotal role in emergency management.

The "9-11" attacks brought painful losses to the United States and were a call to guard against magnitude emergencies worldwide. The SARS virus greatly threatened the lives and property of people all over the world. The outbreak, spread, and continuous development of the COVID-19 have plunged the world into a protracted conflict and brought serious damage to the world. At present, the world faces volatility, uncertainty, complexity, ambiguity (VUCA), and unpredictable events are becoming more frequently, which pose a potential but unpredictable serious threat to sustainable development. The highly complex governance scenarios, the uncertainty of magnitude emergencies, and the limitation of risk governance led to emergency failure of the government. It is necessary to mobilize social organizations and the public to participate in collective actions to improve the emergency quality and efficiency [3]. Countries all over the world are actively exploring the emergency management of magnitude emergencies and have formed different characteristics and models, and China is no exception. The large-scale SNEM formed through social mobilization is an essential feature of emergency management and a potent weapon, helping China to overcome many emergencies. The SNEM generated in this process is considered an effective form of organization to deal with magnitude emergencies. In the fight against the COVID-19, the Chinese government launched a wide range of social mobilization, calling on social organizations and the public quickly to reach substantive cooperation with the government, establish the broad SNEM, and work together to effect 
major change through the network. The cooperation of multiple subjects prevented the spread and development of the epidemic in a short period.

Due to the attributes of collective activities, heterogeneity among organizations, and interest differences among subjects and limited rationality in emergency management, each subject in the SNEM has repeated game behavior; that is, each subject will constantly adjust their own strategy according to different emergency scenarios and the strategy changes of other subjects [4]. The different strategy combinations led to varying structures and functions of the SNEM, resulting in various emergency management results [5]. Analyzing different types of the SNEM and cracking the internal logic of the formation of the "black box" are conducive to better grasping the formation law, building the SNEM that highly matches the emergency scenarios, and realizing the coincidence of emergency demands and network functions. At present, there are few studies on the SNEM, especially on the generation mechanism, subject game, and strategy selection of the SNEM. On this basis, taking China as an empirical sample, aiming at the governance scenarios under magnitude emergencies, this paper uses the evolutionary game model to study the game process and strategy selection among the government, social organizations, and the public in the SNEM. The research attempted to answer the following questions: (1) Can the SNEM be divided into several types, and what is the basis for its division? (2) What are the scenarios and generation mechanism of cooperation among subjects in the SNEM? (3) What are the game processes in the SNEM, and how do emergency subjects make their selections? Through the investigation of these problems, this paper aims to explore the game law among subjects in the SNEM, analyze the strategy combination and evolutionary path of different emergency mobilization, and seek the optimal solution of strategy selection, so as to provide theoretical guidance and practical support for the strategy selection of emergency mobilization.

\section{Literature Review}

At present, the studies related to social network are mainly divided into two categories: social network as research methods or research objects; this paper is the latter. The studies on social network as the object are mainly concentrated in community governance, emergency management, and public services [6-10]. In emergency management, few people have directly focused on the SNEM, but the studies related to social network are relatively rich and mainly focus on the construction, types, functions, and organizational analysis of social network.

2.1. Emergence of Social Network. As regards the emergence, social networks are a form of governance that coordinate and cooperate with each other based on certain conditions under the double superposition of the nature of collective action and internal and external factors of the actors and their relationship attributes [11]. The essence of collective action is the interdependence of tasks and resources between network organizations [5]. The willingness to cooperate between actors is affected by homogeneity, geographic proximity, and trust [12-15]. In public and nonprofit sectors, the generating conditions are usually in the form of controlling public resources, whereas, in the private sector, they are usually in the form of signing formal contracts, and the network is usually structured by a top-down approach [16].

2.2. Classification of Social Network. As regards the classification of social network under different standards, based on their stability, governance model, hierarchical structure, and construction procedures, social network can be divided into different types. According to the stability and the willingness of cooperation among their actors, social network can be divided into the incentive-compatible, stable, and comprehensive cooperation type or one-way pay, onesided noncooperation type [4]. Social network can also be divided into the shared or participatory governance, governed leading organizations, and governed network management organizations based on the governance model, with each network performing different functions. Next, social network is also divided into the intraorganizational type, interorganizational type, and cross-level type based on network boundaries and the closeness of connections between different types of organizations [1]. Then, according to the construction procedure, social network is also divided into the top-down type and bottom-up type. The former usually exists in public and nonprofit sectors and is occasionally compulsory [8], whereas the latter is usually created informally by network members and is voluntary [17].

2.3. Role of Social Network. As regards the role, social network has the functions of reducing costs, creating social capital, promoting collective action, and enhancing public value. Social network helps in building trust, establishing reciprocal norms, and obtaining funds and other resources through information exchange and cooperation between organizations, thereby reducing transaction costs $[18,19]$. As an integral part of social capital, the construction and development of social network strengthen the communication and assistance among different organizations and improve the stock of social capital by building trust [20]. Social network also promotes social capital while connecting actors with common interests, information, and skills necessary for organizational actions, promoting a lasting collective action [21-24]. However, several scholars have pointed out that social network also has disadvantages. Given the homogeneity and geographic proximity of social network, homogeneous clusters easily formed in the wider network, which is not conducive to cooperation and coordination between different organizations [5].

2.4. Organizations (Subjects) of Social Network. Organizations in the social network mainly include the government, social organizations, the public, and international institutions [9]. Each subject can act as the core 
subject in the network, but usually, the government acts as the core subject of the network. Most of the studies on the role of organizations are measured and analyzed by structural indicators such as centrality and density [25]. When the organization is at the centre of the network, its structural position plays a more obvious role [26]. Organizations can achieve their specific goals by adjusting their own behavioral strategy (such as cooperation and non-cooperation) to change the network structures to achieve their specific goals [27], while the social network structure will, in turn, affect the subject behavior strategy [28]. This phenomenon occurs in emergency mobilization and is reflected in fields such as public participation [29].

Generally, the existing literature has two deficiencies. First, the existing studies mainly analyze the various effects of the network itself and the organizational structure embedded in the network from a static perspective and lack a dynamic perspective to analyze the construction mechanism of the network. Second, the lack of classification of the SNEM has led to the inability to choose effectively and reduced the effectiveness of emergency management. The possible innovations are embodied in two aspects. First, it uses game theory to analyze the strategy selection of different subjects in the network and discusses the operation mechanism of the SNEM. Second, it puts forward the classification standard, analyzes four types of the SNEM, and points out the best type.

\section{Types and Generation Mechanism of the SNEM in Magnitude Emergencies}

In the face of "black swan" incidents, the public's emergency awareness is awakened, causing an emergency force to emerge with individuals or organizations as the unit and forming the SNEM under the corresponding emergency mobilization mechanism. However, given the differences in the collective action attribute of emergency management and the interest orientation of multiple subjects, different situations arise regarding the willingness to cooperate and strategy selections between the subjects and objects, thereby forming different types of the SNEM. Taking the path of social mobilization for emergency as the first-level indicator, and the types of participants and the willingness to cooperate among different subjects as the second-level indicators, the SNEM is divided into four categories: symbiotic type or conflict type under the top-down mobilization, and binary type or discrete type under the bottom-up mobilization. This paper only discusses the willingness to cooperate between the government and social organizations or the public, which is used as the basis for the classification of the SNEM, without considering the willingness to cooperate between the public and social organizations.

3.1. SNEM under the High-Intensity Mobilization Path. In the complex governance scenarios, the government conducts the high-intensity emergency social mobilization for the public and social organizations to form the high-density and integrated SNEM among the government, social organizations, and the public. Under the high-intensity mobilization path, the SNEM is divided into two types according to the willingness of social organizations and the public: symbiotic type or conflict type.

3.1.1. Symbiotic SNEM. The symbiotic SNEM means that, under the high-intensity emergency mobilization by the government, social organizations and the public respond positively, mobilize their own, and cooperate positively with the government's commands and coordination, forming the "one nuclear and multiple" SNEM with government-centric, social organization, and the public-participation. The network has the characteristic of symbiosis, which means that, in the SNEM, the development and conduct of activities of each subject depend on the assistance and support of the other subjects, and the subjects have a mutual dependence and joint promotion relationship (Figure 1). The role of the government in the symbiotic SNEM mainly includes the makers of emergency decision, the trustee of emergency services, and the commander and coordinator of emergency work. In emergencies, the dilemma of "government failure" and the complexity of the governance scenarios cause difficulty for the government to resist disasters on its own. However, the government can use its own advantages and power to make rapid and scientific emergency decisions. The government also entrusts the production and provision of emergency services to share its burden and save emergency costs and maintain the emergency order through the command and coordination of multiple emergency subjects [30]. The public's response to the government's mobilization in emergency management mainly includes independent participation and organized participation. The public's independent participation is achieved mainly through emergency social mobilization to enable the public to consciously cooperate with the government and encourage the public to form or change certain values, attitudes, and expectations. The public's organized participation occurs mainly through the community, which is a public self-government platform and the basic unit of public life, to respond to emergency mobilization and conduct emergency management in an organized manner under the leadership of the community's party committee and with the help of social organizations.

The forms of social organizations responding to the government's mobilization in emergency management mainly include assisting the government in decision-making, connecting the government and the public, collecting and distributing materials. As an intermediate force between the government and the public, social organizations help the government realize the matching of emergency information supply and public emergency information demand [31,32]. Through the analysis of the responsibility and role division of the subjects in the symbiotic SNEM, it is not difficult to see that, in the SNEM, the subjects are interdependent and supported, showing the characteristics of high density and strong adhesion.

3.1.2. Conflict SNEM. The conflict SNEM means that, under the high-intensity emergency mobilization by the 


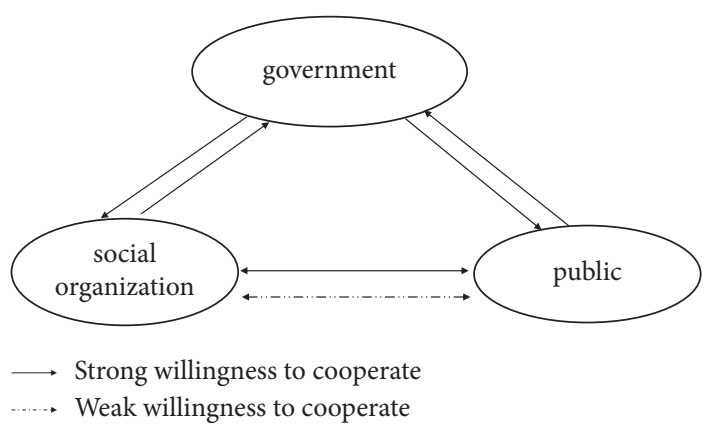

Figure 1: Schematic diagram of the symbiotic SNEM.

government, social organizations and the public, or one of them, have adopted the strategy of negative response. Under this path, the government strives to establish cooperative relations with social organizations for emergency cooperation through efforts such as empowerment and coordination and mobilizes the public to participate through media propaganda and offline calls. However, social organizations and the public are affected by different interest orientations and fail to respond to the government's mobilization positively. The network also has the characteristics of conflict, because the low willingness to cooperate leads to the goal conflict among subjects. Based on the degree of willingness of social organizations and the public to respond to the government's mobilization, the conflict SNEM can be divided into three types (Figures 2(a) to 2(c)).

(1) When social organizations respond positively, the public's willingness to respond is not high. At this point, social organizations use their professional advantages to assist the government positively in the emergency decision-making, use their grassroot advantages to deepen the "last mile" for emergency communication and emergency information searching, and fully use the social organization resource system for emergency supplies. In the context of emergency management of magnitude emergencies, it is generally necessary for the public to change their previous life and work style to improve the emergency efficiency and quality quickly. However, the public often habitually wants to maintain the original life and work style, and the enthusiasm and initiative to make changes are not high, so it will also show a low willingness to respond to the government's mobilization (Figure 2(a)).

(2) When the public responded positively, social organizations were not willing to respond. At this point, the public restrict their own behavior, cooperate positively with the government's emergency decisions, and participate in the emergency management in the form of individuals and organizations by means of donations and acting as volunteers. However, social organizations show a low willingness to cooperate or take negative actions to ignore the crisis or act according to their own will to carry out emergency work (Figure 2(b)).
(3) When the public and social organizations' willingness to respond is low, at this point, the government helps social organizations and the public cooperate in emergency management by publishing information and providing resources quickly. However, due to the low willingness of social organizations and the public to respond to the government's mobilization, the social responsiveness is poor, easily leading to the dilemma of "fragmented" in emergency management. An information gap occurs between government and society, introducing difficulties in ensuring the quality of emergency response.

3.2. SNEM under the Low-Intensity Mobilization Path. Affected by various factors, such as the traditional government's "take on everything" emergency management and the weak awareness of emergency [8], the government also has a negative mobilization during magnitude emergencies. In this situation, the government has low responsiveness, and the public in emergency response is low. However, with the enhancement of emergency management capabilities in China, the establishment of a limited government, and the development and maturity of civil society, a bottom-up social automobilization model has gradually taken shape. Both play an increasingly important role in the risky society with complexity and turbulence. Therefore, under the lowintensity mobilization path, the SNEM can be divided into the binary type or discrete type according to the willingness to cooperate among the subjects.

3.2.1. Binary SNEM. The binary SNEM refers to the low willingness of the government, while social organizations and the public have a high willingness to cooperate, thereby forming the "government-society" binary SNEM (Figure 3). In this type, the government either responds negatively or follows the traditional administrative-controlled path to take care of all aspects of emergency work. Social organizations mobilize themselves positively, combine superior resources, and provide guidance and organizational guarantee for public participation in emergency work. Through active selfmobilization, the public form a high awareness of cogovernance and carry out orderly emergency work by assisting and participating in social organizations. Based on self- 


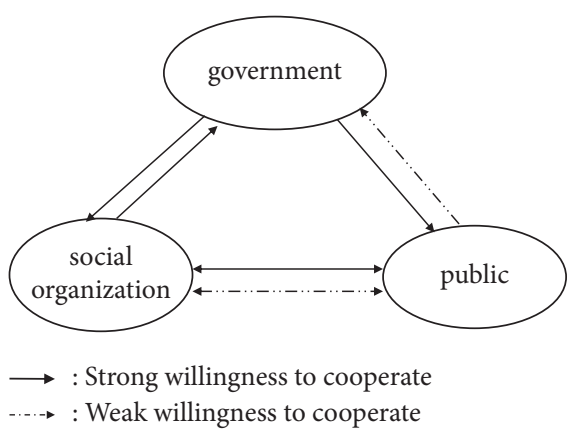

(a)

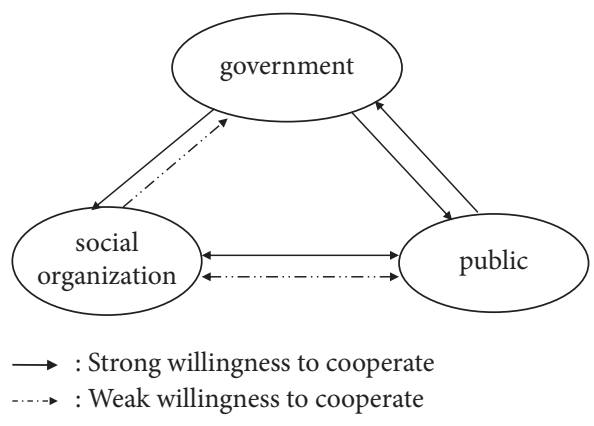

(b)

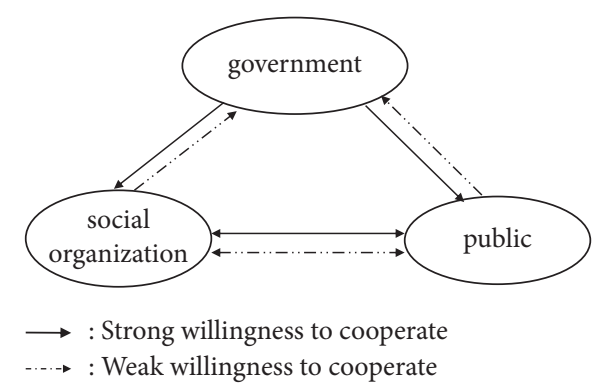

(c)

Figure 2: Schematic diagram of the conflict SNEM.

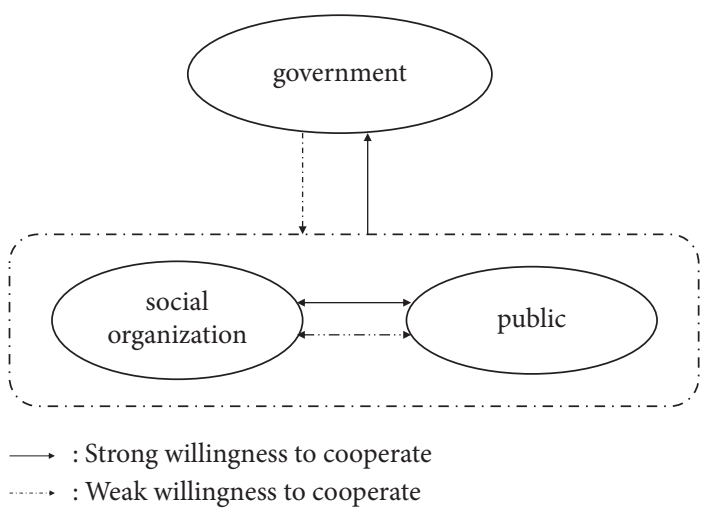

FIGURE 3: Schematic diagram of the binary SNEM.

mobilization, the public and social organizations carry out emergency work by establishing a cooperative partnership and assist and supervise the government's emergency work.

3.2.2. Discrete SNEM. The discrete SNEM refers to the active self-mobilization by social organizations and the public, when the willingness of the government's mobilize is low. In this case, the willingness to cooperate is low, and at most, a kind of subject seeks to cooperate with the government, leading to the loose cooperation among emergency subjects, forming the discrete SNEM (Figures 4(a) to 4(c)). This network presents discrete characteristics due to the high willingness to self-mobilize and low willingness to cooperate among subjects.
(1) Social organizations seek to cooperate positively with the government, but the public's willingness to cooperate is low. In this type, social organizations provide various resources for emergency positively by self-mobilization, but the government does not recognize it and shows low responsiveness. The public have low willingness to cooperate because of self-mobilization and are unwilling to sacrifice their own interests to cooperate with the government (Figure 4(a)).

(2) The public seek to cooperate positively with the government, but the willingness of social organizations to cooperate is low. In this type, the public cooperate with the government positively based on self-mobilization and assist the government through 


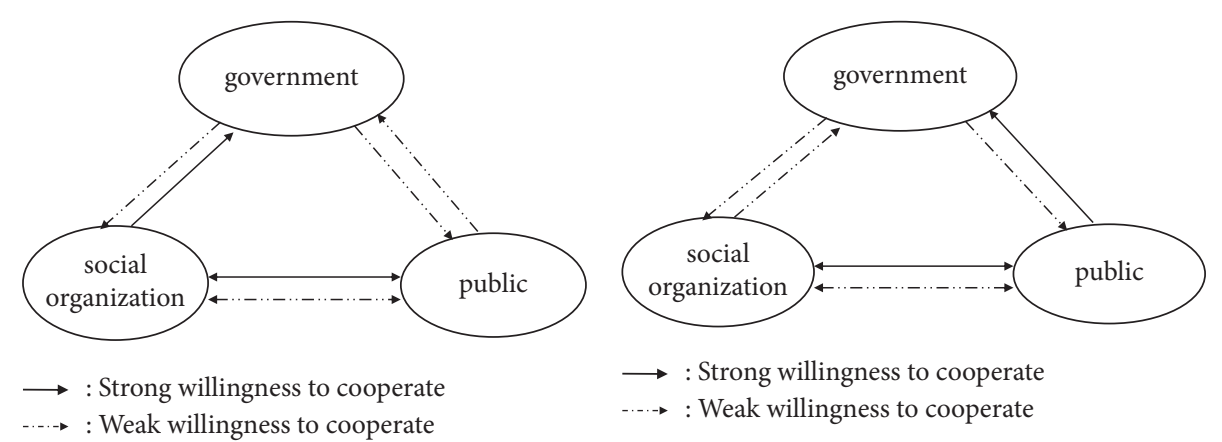

(a)

(b)

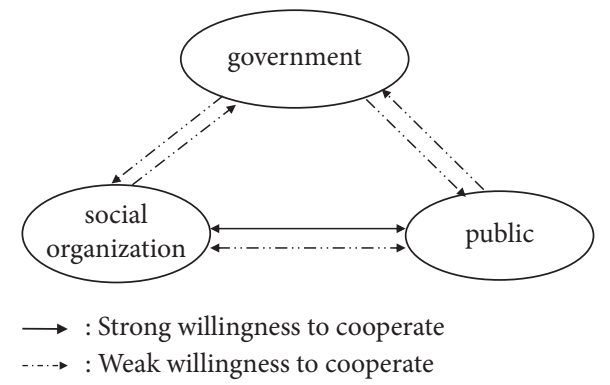

(c)

Figure 4: Schematic diagram of the discrete SNEM.

donations, advice, and suggestions. However, the government shows low responsiveness to these actions, whereas social organizations show distrust and refuse to cooperate with the government (Figure 4(b)).

(3) The public, social organizations, and the government all show low willingness to cooperate. In this type, the government, social organizations, and the public failed to form a scientific and reasonable division of labor due to the lack of information exchange platform and mechanism. As a result, the government undertakes too many responsibilities and functions, social organizations cannot give full play to their professional advantages quickly, and the public cannot respond to emergency measures in time. So, there is no efficient cooperation pattern among subjects, which affects the efficiency and effectiveness of emergency management (Figure 4(c)).

3.3. Summary. In summary, according to the cooperation intensity among subjects, the SNEM is divided into four categories. In China, the SNEM will be affected by the interaction between the vertical network controlled by the central government and the horizontal network created by members, thus forming the multiple SNEM with the topdown or bottom-up. The purpose of constructing the SNEM is to promote multiple subjects to participate in the collective actions of emergency management. However, due to the heterogeneity of subjects and different interests, the cooperation in the SNEM presents the characteristics of limited rationality, and different subjects will make new strategy selection according to the behavior changes of other subjects. Therefore, it is more realistic to use evolutionary game to analyze the cooperation of the government, social organizations, and the public in the SNEM (Table 1).

\section{Evolution Game Analysis of the SNEM}

4.1. Model Assumptions. In China, the social mobilization for magnitude emergencies is generally initiated by the government and responded or participated by social organizations and the public. In this process, the game subjects are the government, social organizations, and the public, which constitute the SNEM. It belongs to a typical social network. Given that the social mobilization for magnitude emergencies has a strong character with emergency and policy, the government must initiate and mobilize the participation of social organizations and the public. The function of social organizations determines that, in many cases, they need to respond positively to government and further mobilize other organizations and individuals. As the subject and object of mobilization, the public have realized the unity of subject and object. It is essential to participate in the social mobilization of magnitude emergencies. Under the premise that information is not completely symmetrical, all subjects in the SNEM are bounded rationality, and there are differences in interest pursuit, which constitutes the asymmetric game scenarios. Among them, the government aims to maximize social interests, while social organizations and the public pursue the maximization of their own interests. Therefore, how to optimize the strategy selection of subjects in asymmetric game scenarios to promote cooperation is essential to finding the optimal game path to overcome social dilemmas. 
TABle 1: Classification of the SNEM.

\begin{tabular}{|c|c|c|c|c|c|}
\hline & \multirow{3}{*}{ Public } & \multicolumn{4}{|c|}{ Social organizations } \\
\hline & & \multicolumn{2}{|c|}{ Response positively } & \multicolumn{2}{|c|}{ Response negatively } \\
\hline & & Participate positively & Participate negatively & Participate positively & Participate negatively \\
\hline \multirow{2}{*}{ Government } & High mobilization intensity & Symbiosis & Conflict & Conflict & Conflict \\
\hline & Low mobilization intensity & Binary & Discrete & Discrete & Discrete \\
\hline
\end{tabular}

Hypothesis 1. The three types of subjects in the SNEM adopt two strategies to participate in emergency mobilization. The government adopts the strategy with the high-intensity or low-intensity, the strategy set is \{high-intensity, low-intensity\}, which is denoted as $\left(G_{1}, G_{2}\right)$, and their probabilities are $x, 1-x(0 \leq x \leq 1)$, respectively. The social organizations adopt the strategy with the positive response or negative response, the strategy set is \{positive response, negative response\}, which is denoted as $\left(S_{1}, S_{2}\right)$, and their probabilities are $y, 1-y(0 \leq y \leq 1)$, respectively. The public adopt the strategy with the positive participation or negative participation, the strategy set is \{positive participation, negative participation $\}$, which is denoted as $\left(P_{1}, P_{2}\right)$, and their probabilities are $z, 1-z(0 \leq z \leq 1)$, respectively.

Hypothesis 2. When the government adopts the high-intensity strategy, the costs paid are $C_{11}$ (the labor cost caused by the high-intensity social mobilization and related subsidies or compensation used to mobilize other subjects), and the benefits obtained are $R_{11}$ (the improvement of public satisfaction and the increase of income allocated by the superior government due to the positive mobilization effect.). It also includes spillover income (the motivation and enthusiasm for public participation caused by the positive mobilization effect have increased, the degree of cooperation with other government measures has increased significantly, the rewards given by the superior government, etc.). When the government adopts the low-intensity strategy, the costs paid are $C_{12}$ (the increase of transaction cost caused by lowintensity mobilization, etc.), which also includes spillover costs (the public distrust and disapproval of the government caused by the failure to obtain a positive mobilization effect, resulting in a significant reduction in the degree of cooperation with other government measures, etc.), and the benefits obtained are $R_{12}$ (general gains without positive mobilization effects, such as normal financial allocations). At this time, $C_{11}>C_{12}, R_{11}>R_{12}$.

Hypothesis 3. When the social organizations adopt the positive response strategy, the costs paid are $C_{21}$ (the cost of mobilizing other organizations and individuals, such as publicity and personnel costs), and the benefits obtained are $R_{21}$ (related subsidies given by the government; new donations and other benefits attracted by social organizations after their reputation has increased, etc.). Given that social organizations respond positively and play a key role in responding to emergencies, the government will also provide certain rewards or subsidies $V_{21}$ (if the government adopts the low-intensity strategy, it will prefer not to give rewards for various reasons). When the social organizations adopt the negative response strategy, the costs paid are $C_{22}$ (the waste of resources caused by the failure of its own function and role due to the negative response, etc.), and the benefits obtained are $R_{22}$ (normal general benefit). However, the social organizations adopt the negative strategy and will generally be punished by the government $F_{21}$ (if the government adopts the low intensity strategy, they may turn a blind eye or take lighter punishments, such as formal persuasion and education, etc.). At this time, $C_{21}>C_{22}, R_{21}>R_{22}$.

Hypothesis 4. When the public adopt the positive participation strategy, the costs paid are $C_{31}$ (the cost of positive participation in social mobilization, such as the opportunity cost caused by time and energy investment, etc.), and the benefits obtained are $R_{31}$ (the psychological satisfaction brought by positive participation in social mobilization, the benefits brought by the restoration of normal production and life order, etc.). When the public adopt the negative participation strategy, the government will give certain subsidies or rewards $W_{31}$ (if the government adopts the low intensity strategy, it will not grant subsidies for various reasons). When the public adopt the negative participation strategy, the costs paid are $C_{32}$ (the losses caused by negative participation in social mobilization, etc.), and the benefits are $R_{32}$ (saving time and other resources due to negative participation, etc.). At this time, $C_{31}>C_{32}, R_{31}>R_{32}$.

Table 2 shows the benefits of the government, social organizations, and the public because of these assumptions.

\subsection{Evolutionary Game Analysis}

4.2.1. Replicated Dynamics Equations of Game Subjects. Combined with Table 2, the expected benefits of each subject under different behavior strategies are as follows:

(1) The expected benefits of the government adopting the high-intensity strategy: 
TABle 2: Game benefits matrix of the government, social organizations, and the public.

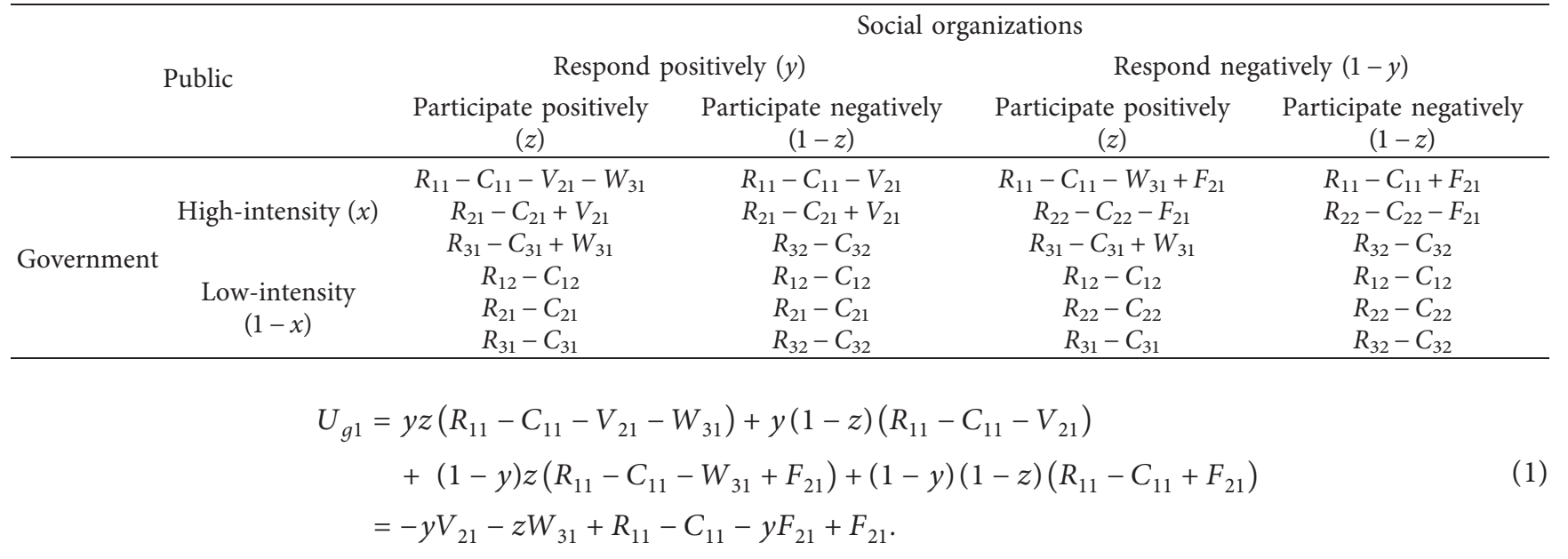

The expected benefits of the government adopting the low-intensity strategy:

$$
\begin{aligned}
U_{g 2}= & y z\left(R_{12}-C_{12}\right)+y(1-z)\left(R_{12}-C_{12}\right) \\
& +(1-y) z\left(R_{12}-C_{12}\right)+(1-y)(1-z)\left(R_{12}-C_{12}\right) \\
= & R_{12}-C_{12} .
\end{aligned}
$$

The average expected benefits of the government: $U_{g}=x U_{g 1}+(1-x) U_{g 2}$.

According to the Malthusian model, the evolutionary game replicated dynamics equation of the government is as follows:

$$
\begin{aligned}
F(x) & =\frac{\mathrm{d}_{x}}{\mathrm{~d}_{t}}=x\left(U_{g 1}-\overline{U_{g}}\right) \\
& =x(1-x)\left[-y\left(F_{21}+V_{21}\right)-z W_{31}+R_{11}-C_{11}-R_{12}+C_{12}+F_{21}\right] .
\end{aligned}
$$

(2) The expected benefits of social organizations adopting the positive response strategy:

$$
\begin{aligned}
U_{S 1}= & x z\left(R_{21}-C_{21}+V_{21}\right)+x(1-z)\left(R_{21}-C_{21}+V_{21}\right) \\
& +(1-x) z\left(R_{21}-C_{21}\right)+(1-x)(1-z)\left(R_{21}-C_{21}\right) \\
= & x V_{21}+R_{21}-C_{21} .
\end{aligned}
$$

The expected benefits of social organizations adopting the negative response strategy

$$
\begin{aligned}
U_{S 2}= & x z\left(R_{22}-C_{22}-F_{21}\right)+x(1-z)\left(R_{22}-C_{22}-F_{21}\right) \\
& +(1-x) z\left(R_{22}-C_{22}\right)+(1-x)(1-z)\left(R_{22}-C_{22}\right) \\
= & -x F_{21}+R_{22}-C_{22} .
\end{aligned}
$$

The average expected benefits of social organizations:

$$
\overline{U_{s}}=y U_{s 1}+(1-y) U_{s 2} .
$$

According to the Malthusian model, the evolutionary game replicated dynamics equation of social organizations is as follows: 


$$
\begin{aligned}
F(y) & =\frac{\mathrm{d}_{y}}{\mathrm{~d}_{t}}=y\left(U_{s 1}-\overline{U_{s}}\right) \\
& =y(1-y)\left[x\left(V_{21}+F_{21}\right)+R_{21}-C_{21}-R_{22}+C_{22}\right] .
\end{aligned}
$$

(3) The expected benefits of the public adopting the positive participation strategy:

$$
\begin{aligned}
U_{p 1}= & x y\left(R_{31}-C_{31}+W_{31}\right)+x(1-y)\left(R_{31}-C_{31}+W_{31}\right) \\
& +(1-x) y\left(R_{31}-C_{31}\right)+(1-x)(1-y)\left(R_{31}-C_{31}\right) \\
= & x W_{31}+R_{31}-C_{31} .
\end{aligned}
$$

The expected benefits of the public adopting the negative participation strategy:

$$
\begin{aligned}
U_{p 2}= & x y\left(R_{32}-C_{32}\right)+x(1-y)\left(R_{32}-C_{32}\right) \\
& +(1-x) y\left(R_{32}-C_{32}\right)+(1-x)(1-y)\left(R_{32}-C_{32}\right) \\
= & R_{32}-C_{32} .
\end{aligned}
$$

The average expected benefits of the public:

$$
\overline{U_{p}}=z U_{p 1}+(1-z) U_{p 2} .
$$

4.2.2. Evolution Stability Analysis of Game Subject Strategy. According to equations (1)-(11), the power system of the subject consisting of the government, social organizations, and the public is as follows: game replicated dynamics equation of the public is as follows:

$$
\begin{aligned}
F(z) & =\frac{\mathrm{d}_{z}}{\mathrm{~d}_{t}}=z\left(U_{p 1}-\overline{U_{p}}\right)=z(1-z)\left(U_{p 1}-U_{p 2}\right) \\
& =z(1-z)\left(x W_{31}+R_{31}-C_{31}-R_{32}+C_{32}\right) .
\end{aligned}
$$

$$
\left\{\begin{array}{l}
\frac{\mathrm{d}_{x}}{\mathrm{~d}_{t}}=x\left(U_{g 1}-\overline{U_{g}}\right)=x(1-x)\left[-y\left(F_{21}+V_{21}\right)-z W_{31}+R_{11}-C_{11}-R_{12}+C_{12}+F_{21},\right. \\
\frac{\mathrm{d}_{y}}{\mathrm{~d}_{t}}=y\left(U_{s 1}-\overline{U_{s}}\right)=y(1-y)\left[x\left(V_{21}+F_{21}\right)+R_{21}-C_{21}-R_{22}+C_{22}\right] \\
\frac{\mathrm{d}_{z}}{\mathrm{~d}_{t}}=z\left(U_{p 1}-\overline{U_{p}}\right)=z(1-z)\left(x W_{31}+R_{31}-C_{31}-R_{32}+C_{32}\right) .
\end{array}\right.
$$


TABle 3: System equilibrium points and eigenvalues.

\begin{tabular}{lccc}
\hline Equilibrium points & $\lambda_{1}$ & Eigenvalues & $\lambda_{3}$ \\
\hline$E_{1}:(0,0,0)$ & $R_{11}-C_{11}-R_{12}+C_{12}+F_{21}$ & $\lambda_{21}-C_{21}-R_{22}+C_{22}$ & $R_{31}-C_{31}-R_{32}+C_{32}$ \\
$E_{2}:(0,0,1)$ & $-W_{31}+R_{11}-C_{11}-R_{12}+C_{12}+F_{21}$ & $R_{21}-C_{21}-R_{22}+C_{22}$ & $-\left(R_{31}-C_{31}-R_{32}+C_{32}\right)$ \\
$E_{3}:(0,1,0)$ & $R_{11}-V_{21}-C_{11}-R_{12}+C_{12}$ & $-\left(R_{21}-C_{21}-R_{22}+C_{22}\right)$ & $R_{31}-C_{31}-R_{32}+C_{32}$ \\
$E_{4}:(0,1,1)$ & $-V_{21}-W_{31}+R_{11}-C_{11}-R_{12}+C_{12}$ & $-\left(R_{21}-C_{21}-R_{22}+C_{22}\right)$ & $-\left(R_{31}-C_{31}-R_{32}+C_{32}\right)$ \\
$E_{5}:(1,0,0)$ & $-\left(R_{11}-C_{11}-R_{12}+C_{12}+F_{21}\right)$ & $V_{21}+R_{21}-C_{21}-R_{22}+C_{22}+F_{21}$ & $W_{31}+R_{31}-C_{31}-R_{32}+C_{32}$ \\
$E_{6}:(1,0,1)$ & $W_{31}-R_{11}+C_{11}+R_{12}-C_{12}-F_{21}$ & $V_{21}+R_{21}-C_{21}-R_{22}+C_{22}+F_{21}$ & $-\left(W_{31}+R_{31}-C_{31}-R_{32}+C_{32}\right)$ \\
$E_{7}:(1,1,0)$ & $V_{21}-R_{11}+C_{11}+R_{12}-C_{12}$ & $-\left(V_{21}+R_{21}-C_{21}-R_{22}+C_{22}+F_{21}\right)$ & $W_{31}+R_{31}-C_{31}-R_{32}+C_{32}$ \\
$E_{8}:(1,1,1)$ & $V_{21}+W_{31}-R_{11}+C_{11}+R_{12}-C_{12}$ & $-\left(V_{21}+R_{21}-C_{21}-R_{22}+C_{22}+F_{21}\right)$ & $-\left(W_{31}+R_{31}-C_{31}-R_{32}+C_{32}\right)$ \\
\hline
\end{tabular}

to $x=0$, and the point under the plane will tend to $x=1$. Similarly, for the social organizations, in plane $V$, that is, the point in $x=C_{21}+R_{22}-C_{22}-R_{21} / V_{21}+F_{21}$ is stable in the $y$-axis direction, the point on the left side of plane $V$ will tend to $y=0$, and the point on the right side of plane $V$ will tend to $y=1$, as shown in Figure 5(b). For the public, in plane $W$, that is, the point in $x=C_{31}-C_{32}-$ $R_{31}+R_{32} / W_{31}$ is stable in the $z$-axis direction, the point on the left side of plane $W$ will evolve towards $z=0$, and the point on the right side of plane $W$ will evolve towards $z=1$, as shown in Figure 5(c).

4.3. Analysis on the Behavior Strategy of the Tripartite Game. $E_{1}:(0,0,0)$ when $\lambda_{1}=R_{11}-C_{11}-R_{12}+C_{12}+F_{21}<0, \lambda_{2}=$ $R_{21}-C_{21}-R_{22}+C_{22}<0$ and $\lambda_{3}=R_{31}-C_{31}-R_{32}+C_{32}<0$, so $(0,0,0)$ is balanced and stable. At this time, the government, social organizations, and the public adopt the low intensity, negative response, and low intensity participation strategy, respectively, which is the most unsatisfactory behavior strategy, corresponding to the discrete SNEM (Figure 4(c)). In the game process, the government fails to adopt the effective social mobilization due to various scruples or limited energy in dealing with magnitude emergencies and could not effectively mobilize other subjects. This will directly lead to the termination of negotiation and maintain the status quo and then lead to the effect of social mobilization being not obvious. Thus, the government needs to reformulate the rules of the game and play again to prompt other subjects to change their strategies. If magnitude emergencies worsen, social organizations and the public may also switch strategies to form the bottom-up type social mobilization, which is different from the type of government-led mobilization, that is, strategies $E_{2}, E_{3}$ and $E_{4}$. However, due to the low intensity strategy adopted by the government at this time, under the constraints of economic rationality, the government will also choose not to mobilize positively or even resist. This type of strategy transformation is the most difficult and depends on a series of institutional conditions.

$E_{2}(0,0,1)$ : when $\lambda_{1}=-W_{31}+R_{11}-C_{11}-R_{12}+C_{12}+$ $F_{21}<0, \lambda_{2}=R_{21}-C_{21}-R_{22}+C_{22}<0$ and $\lambda_{3}=-\left(R_{31}-C_{31}\right.$ $\left.-R_{32}+C_{32}\right)<0$, so $(0,0,1)$ is balanced and stable. At this time, the public, social organizations, and the government adopt the positive participation, negative response, and low-intensity strategy, respectively, which correspond to the discrete SNEM (Figure 4(b)). This type of social network corresponds to the subject strategy, and the public is in a relatively passive position; they cannot obtain the government support nor the favor of social organizations. If effective measures are implemented in time, the public will quickly turn to strategy $E_{1}$, that is, the worst state. If the community where the public is located or the private group formed can select opinion leaders to participate in lobbying based on full consideration of public opinions, the public may also turn to strategy $E_{4}$, but turning to strategies $E_{8}$ or $E_{6}$ is more difficult.

$E_{3}$ : $(0,1,0)$ : when $\lambda_{1}=R_{11}-V_{21}-C_{11}-R_{12}+C_{12}<0$, $\lambda_{2}=-\left(R_{21}-C_{21}-R_{22}+C_{22}\right)<0$ and $\lambda_{3}=R_{31}-C_{31}-R_{32}$ $+C_{32}<0$, so $(0,1,0)$ is balanced and stable. At this time, social organizations, the public, and the government adopt the positive response, negative participation, and low-intensity strategy, respectively, which corresponds to the discrete SNEM (Figure 4(a)). This type of social network corresponds to the subject strategy, where social organizations are in a relatively passive position; that is, they cannot obtain the support by the government nor can they gain public trust. If effective measures are implemented in time, they will quickly turn to strategy $E_{1}$, which is the worst state. However, if social organizations use their professional advantages to lobby through efforts such as propaganda and display to obtain support from the government, they will turn to the more favorable strategy $E_{7}$. If social organizations can continue to persuade the public with the government through practices such as preaching and persuasion, warning them about the importance and necessity of participating in magnitude emergencies, and mobilize them to switch strategy and participate positively, they will turn to the most ideal strategy $E_{8}$ to maximize the benefits of cooperation.

$E_{4}:(0,1,1)$ : when $\lambda_{1}=-V_{21}-W_{31}+R_{11}-C_{11}-R_{12}$ $+C_{12}<0, \quad \lambda_{2}=-\left(R_{21}-C_{21}-R_{22}+C_{22}\right)<0$ and $\lambda_{3}=-$ $\left(R_{31}-C_{31}-R_{32}+C_{32}\right)<0$, so $(0,1,1)$ is balanced and stable. At this time, social organizations, the public, and the government adopt the positive response, positive participation, and low-intensity strategy, respectively, which correspond to the dual-type SNEM (Figure 3). This type of social network corresponds to the subject strategy, where social organizations and the public reach a consensus and adopt a positive attitude to participate in social mobilization. This mobilization can often achieve remarkable success in 


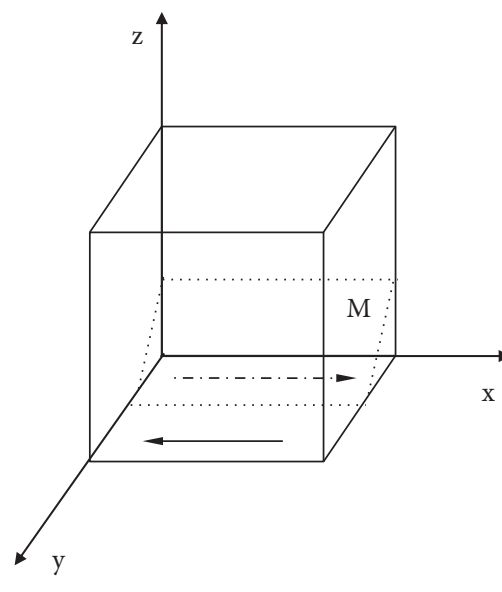

(a)

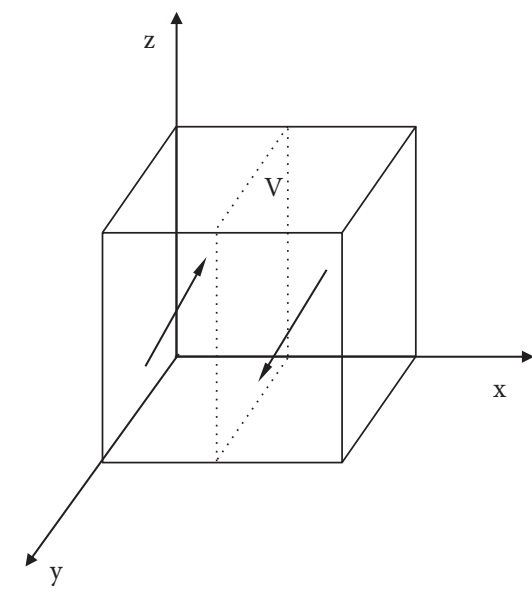

(b)

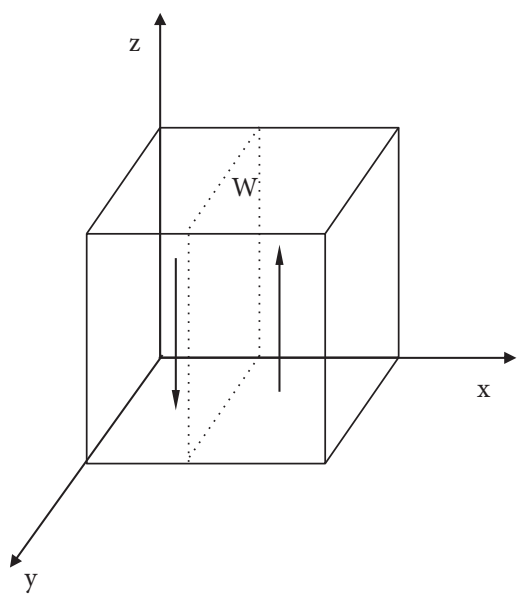

(c)

Figure 5: Evolutionary process of government, social organizations, and the public. (a) Evolution process of government strategy. (b) Evolution process of social organizations strategy. (c) Evolution process of the public strategy.

communities with a high degree of autonomy. If the government adopts the low-intensity strategy, the emergency social mobilization is often interrupted or stopped due to the lack of government support and promotion, which is generally difficult to continue. However, social organizations and the public will also negotiate with the government, aiming to persuade the government through various means to achieve the transition to the most ideal strategy $E_{8}$.

$E_{5}:(1,0,0)$ : when $\lambda_{1}=-\left(R_{11}-C_{11}-R_{12}+C_{12}+F_{21}\right)$ $<0, \quad \lambda_{2}=V_{21}+R_{21}-C_{21}-R_{22}+C_{22}+F_{21}<0 \quad$ and $\lambda_{3}=W_{31}+R_{31}-C_{31}-R_{32}+C_{32}<0$, so $(1,0,0)$ is balanced and stable. At this time, the government, social organizations, and the public adopt the high-intensity, negative response, and negative participation strategy, respectively, which correspond to the conflict SNEM (Figure 2(c)). At this time, the government promotes positively, but the attitude of social organizations and the public is extremely negative and may result in their nonparticipation. The possible reasons are as follows: on the one hand, the government does not publicize the importance and necessity of emergency social mobilization, participation in the mobilization requires considerable public energy, and the public assumes a negative attitude; on the other hand, social organizations perceive the noncooperation of the public or their negative attitudes and may have trouble in participating in social mobilization continually. Thus, they may also decide not to participate in the strategy. In this game process, given that both parties adopt a negative attitude of participation, this type of cooperation is often difficult to achieve without the help of administrative authority.

$E_{6}:(1,0,1)$ : when $\lambda_{1}=W_{31}-R_{11}+C_{11}+R_{12}-C_{12}-F_{21}$ $<0, \quad \lambda_{2}=V_{21}+R_{21}-C_{21}-R_{22}+C_{22}+F_{21}<0 \quad$ and $\lambda_{3}=-\left(W_{31}+R_{31}-C_{31}-R_{32}+C_{32}\right)<0$, so $(1,0,1)$ is balanced and stable. At this time, the government, the public, and social organizations adopt the high-intensity, positive participation, and negative response strategy, respectively, which correspond to the conflict SNEM (Figure 2(b)). This type of social network corresponds to the subject strategy, where the government and the public reach a consensus on emergency social mobilization, which is generally manifested as movement mobilization. However, at this point, social organizations have low enthusiasm for participation; they even refuse to participate. Organizational participation costs are extremely high, no other capital injection is available, economic pressure is high, or certain behaviors are inconsistent with the organizations' tasks and missions, and they cannot be recognized by members of social organizations.

$E_{7}:(1,1,0)$ : when $\lambda_{1}=V_{21}-R_{11}+C_{11}+R_{12}-C_{12}<0$, $\lambda_{2}=-\left(V_{21}+R_{21}-C_{21}-R_{22}+C_{22}+F_{21}\right)<0$ and $\lambda_{3}=W_{31}$ $+R_{31}-C_{31}-R_{32}+C_{32}<0$, so $(1,1,0)$ is balanced and stable. At this time, the government, social organizations, and the public adopt the high-intensity, positive response, and negative participation strategy, respectively, which correspond to the conflict SNEM (Figure 2(a)). This type of social network corresponds to the subject game strategy, where the government and social organizations reach a consensus to adopt a wide range of mobilization in response to magnitude emergencies, and the public's negative participation strategy may affect the mobilization effect to a certain extent. However, given the authority and organizational advantages of the government and social organizations, some community members could be potentially mobilized to engage in public participation in a relatively short period, prompting them to shift quickly and turn to the most ideal strategy $E_{8}$.

$E_{8}:(1,1,1)$ : when $\lambda_{1}=V_{21}+W_{31}-R_{11}+C_{11}+R_{12}-$ $C_{12}<0, \lambda_{2}=-\left(V_{21}+R_{21}-C_{21}-R_{22}+C_{22}+F_{21}\right)<0$ and $\lambda_{3}=-\left(W_{31}+R_{31}-C_{31}-R_{32}+C_{32}\right)<0$, so $(1,1,1)$ is balanced and stable. At this time, the government, social organizations, and the public adopt the high-intensity, positive response, and positive participation strategy, respectively, which correspond to the symbiotic SNEM (Figure 1). This type of social network corresponds to the subject strategy, where the three subjects reach a consensus. In response to magnitude emergencies, all subjects are mobilized positively, 
forming a situation of widespread mobilization of the entire society. Generally, it can quickly release the positive effect of emergency social mobilization in a short time. With the COVID-19 epidemic as an example, China has contributed Chinese experience and solutions to the world. The important aspects of such contributions are adopting a wide range of emergency social mobilization, selecting strategy $E_{8}$, and achieving an ideal state.

\section{Conclusion}

Taking China as a sample, this paper analyzed the evolutionary game of the SNEM and explored the internal generation mechanism, subject game, and their strategy selections. In recent years, the outbreak of magnitude emergencies, such as the COVID-19, Ebola epidemic, and Zika virus, has caused severe damage to countries worldwide. In the face of frequent magnitude emergencies in the context of a risky society, countries all over the world are actively exploring new programs for efficient and timely emergency management. In this context, combined with Chinese practice, this paper analyzed the SNEM and its game and drew the following conclusion: (1) the SNEM, where the government, social organizations, and the public adopt the high-intensity, positive response, and positive participation strategy, respectively, is the most ideal network; (2) the SNEM, where the government, social organizations, and the public adopt the low intensity, negative response, and negative participation strategy, respectively, is the worst network; (3) however, different types of the SNEM are not fixed, and dynamic transformation can be realized by guiding the subject behavior strategy. Through the empirical analysis of the types, generation mechanism, subject behavior, and strategy selection of the SNEM in China, this paper seeks the optimal strategy of social mobilization matching the emergency scenarios based on utility maximization, in order to provide useful reference for emergency social mobilization in magnitude emergencies all over the world and contribute Chinese wisdom and China's plans to the world.

\section{Data Availability}

The data used to support the findings of the study are available from the corresponding author upon request.

\section{Conflicts of Interest}

The authors declare that they have no conflicts of interest.

\section{Acknowledgments}

The authors are extremely grateful to Ouyang Fan for her many helpful suggestions. This study was supported by the Fundamental Research Funds for the Central Universities (Grant no. 2021SKWF04) and Beijing Social Science Foundation (Grant no. 20GLC044).

\section{References}

[1] P. Kenis and K. G. Provan, "Towards an exogenous theory of public network performance," Public Administration, vol. 87, no. 3, pp. 440-456, 2009.

[2] N. Rui and O. Y. Fan, "Influence of social networks on citizens' willingness to participate in social governance: evidence from China," Complexity, vol. 2020, Article ID 3819514, 16 pages, 2020.

[3] D. Nohrstedt, "Explaining mobilization and performance of collaborations in routine emergency management," Administration \& Society, vol. 48, no. 2, pp. 135-162, 2016.

[4] V. Bala and S. Goyal, "A noncooperative model of network formation," Econometrica, vol. 68, no. 5, pp. 1181-1229, 2000.

[5] A. Sapat, A.-M. Esnard, and A. Kolpakov, "Understanding collaboration in disaster assistance networks: organizational homophily or resource dependency?" The American Review of Public Administration, vol. 49, no. 8, pp. 957-972, 2019.

[6] J. S. Coleman, "Social capital in the creation of human capital," American Journal of Sociology, vol. 94, pp. 95-120, 1988.

[7] E. W. Lee and H. K. Liu, "Factors influencing network formation among social service nonprofit organizations in Hong Kong and implications for comparative and China studies," International Public Management Journal, vol. 15, no. 4, pp. $454-478,2012$.

[8] K. G. Provan and K. Huang, "Resource tangibility and the evolution of a publicly funded health and human services network," Public Administration Review, vol. 72, no. 3, pp. 366-375, 2012.

[9] K. G. Provan, K. Huang, and H. B. Milward, "The evolution of structural embeddedness and organizational social outcomes in a centrally governed health and human services network," Journal of Public Administration Research and Theory, vol. 19, no. 4, pp. 873-893, 2009.

[10] J. P. Breimo, H. Turba, O. Firbank, I. Bode, and J. T. Sandvin, "Networking enforced-comparing social Services' collaborative rationales across different welfare regimes," Social Policy and Administration, vol. 51, no. 7, pp. 1348-1366, 2017.

[11] D. Nohrstedt and Ö. Bodin, "Collective action problem characteristics and partner uncertainty as drivers of social tie formation in collaborative networks," Policy Studies Journal, vol. 48, no. 4, pp. 1082-1108, 2020.

[12] Y. C. Atouba and M. Shumate, "International nonprofit collaboration," Nonprofit and Voluntary Sector Quarterly, vol. 44, no. 3, pp. 587-608, 2015.

[13] J. A. Musso and C. Weare, "From participatory reform to social capital: micro-motives and the macro-structure of civil society networks," Public Administration Review, vol. 75, no. 1, pp. 150-164, 2015.

[14] E. R. Gerber, A. D. Henry, and M. Lubell, "Political homophily and collaboration in regional planning networks," American Journal of Political Science, vol. 57, no. 3, pp. 598-610, 2013.

[15] M. Granovetter, "Economic Action and Social Structure," The Problem of Embeddedness, Routledge, London, UK, 2018.

[16] K. G. Provan and P. Kenis, "Modes of network governance: structure, management, and effectiveness," Journal of Public Administration Research and Theory, vol. 18, no. 2, pp. 229252, 2008.

[17] N. Lin, Y. C. Fu, and R. M. Hsung, "The Position Generator," Measurement Techniques for Investigations of Social Capital, Routledge, London, UK, 2001.

[18] N. Lin, "A network theory of social capital," The Handbook of Social Capital, Oxford University Press, Oxford, UK, 2008. 
[19] R. D. Putnam, R. Leonardi, and R. Y. Nanetti, Making Democracy Work, Princeton University Press, Princeton, NJ, USA, 1994.

[20] A. Rosenberg, K. Hartwig, and M. Merson, "GovernmentNGO collaboration and sustainability of orphans and vulnerable children projects in southern Africa," Evaluation and Program Planning, vol. 31, no. 1, pp. 51-60, 2008.

[21] M. S. Granovetter, "The strength of weak ties," American Journal of Sociology, vol. 78, no. 6, pp. 1360-1380, 1973.

[22] P. E. Oliver and G. Marwell, "The paradox of group size in collective action: a theory of the critical mass. II," American Sociological Review, vol. 53, no. 1, pp. 1-8, 1988.

[23] R. D. Putnam, Bowling Alone: The Collapse and Revival of American Community, Simon \& Schuster, New York, NY, USA, 2000.

[24] R. D. Putnam, L. Feldstein, and D. J. Cohen, Better Together: Restoring the American Community, Simon \& Schuster, New York, NY, USA, 2004.

[25] M. D. Siciliano and J. R. Thompson, "If you are committed, then so am I: the role of social networks and social influence on organizational commitment," Administration and Society, vol. 50, no. 7, pp. 916-946, 2018.

[26] I. Luxton and J. Sbicca, "Mapping movements: a call for qualitative social network analysis," Qualitative Research, vol. 21, no. 2, pp. 161-180, 2021.

[27] N. Holman, "Community participation: using social network analysis to improve developmental benefits," Environment and Planning C: Government and Policy, vol. 26, no. 3, pp. 525-543, 2008.

[28] C. Wukich, M. D. Siciliano, J. Enia, and B. Boylan, "The formation of transnational knowledge networks on social media," International Public Management Journal, vol. 20, no. 3, pp. 381-408, 2017.

[29] S. Schnell and J. Saxby, "Mobilizing against hunger and poverty: capacity and change in a Brazilian social mobilization network," Public Administration and Development, vol. 30, no. 1, pp. 38-48, 2010.

[30] F. Xiong, X. Wang, S. Pan, H. Yang, H. Wang, and C. Zhang, "Social recommendation with evolutionary opinion dynamics," IEEE Transactions on Systems, Man, and Cybernetics: Systems, vol. 50, no. 10, pp. 3804-3816, 2018.

[31] Y. Hu, F. Xiong, S. Pan, X. Xiong, L. Wang, and H. Chen, "Bayesian personalized ranking based on multiple-layer neighborhoods," Information Sciences, vol. 542, pp. 156-176, 2021.

[32] F. Xiong, W. Shen, H. Chen, S. Pan, X. Wang, and Z. Yan, "Exploiting implicit influence from information propagation for social recommendation," IEEE Transactions on Cybernetics, vol. 50, no. 10, pp. 4186-4199, 2019. 